Article

\title{
Toxicity and Synergistic Effect of Elsholtzia ciliata Essential Oil and Its Main Components against the Adult and Larval Stages of Tribolium castaneum
}

\author{
Jun-Yu Liang *, Jie Xu, Ying-Ying Yang, Ya-Zhou Shao, Feng Zhou and Jun-Long Wang \\ School of Life Science, Northwest Normal University, Lanzhou 730070, Gansu, China; \\ XJ13893279431@163.com (J.X.); y17339832389@163.com (Y.-Y.Y.); 18893811951@163.com (Y.-Z.S.); \\ fengzhou@nwnu.edu.cn (F.Z.); wangjunlong@nwnu.edu.cn (J.-L.W.) \\ * Correspondence: liangjunyu@nwnu.edu.cn
}

Received: 11 February 2020; Accepted: 10 March 2020; Published: 16 March 2020

\begin{abstract}
Investigations have indicated that storage pests pose a great threat to global food security by damaging food crops and other food products derived from plants. Essential oils are proven to have significant effects on a large number of stored grain insects. This study evaluated the contact toxicity and fumigant activity of the essential oil extract from the aerial parts of Elsholtzia ciliata and its two major biochemical components against adults and larvae of the food storage pest beetle Tribolium castaneum. Gas chromatography-mass spectrometry analysis revealed 16 different components derived from the essential oil of E. ciliata, which included carvone (31.63\%), limonene $(22.05 \%)$, and $\alpha$-caryophyllene (15.47\%). Contact toxicity assay showed that the essential oil extract exhibited a microgram-level of killing activity against $T$. castaneum adults (lethal dose $50\left(\mathrm{LD}_{50}\right)=$ $7.79 \mu \mathrm{g} /$ adult $)$ and larvae $\left(\mathrm{LD}_{50}=24.87 \mu \mathrm{g} /\right.$ larva $)$. Fumigant toxicity assay showed $\mathrm{LD}_{50}$ of $11.61 \mathrm{mg} / \mathrm{L}$ air for adults and $8.73 \mathrm{mg} / \mathrm{L}$ air for larvae. Carvone and limonene also exhibited various levels of bioactivity. A binary mixture (2:6) of carvone and limonene displayed obvious contact toxicity against $T$. castaneum adults $\left(\mathrm{LD}_{50}=10.84 \mu \mathrm{g} /\right.$ adult $)$ and larvae $\left(\mathrm{LD}_{50}=30.62 \mu \mathrm{g} / \mathrm{larva}\right)$. Furthermore, carvone and limonene exhibited synergistic fumigant activity against $T$. castaneum larvae at a 1:7 ratio. Altogether, our results suggest that E. ciliata essential oil and its two monomers have a potential application value to eliminate $T$. castaneum.
\end{abstract}

Keywords: Elsholtzia ciliata; Tribolium castaneum; essential oil; carvone; limonene; insecticidal activity; synergistic effect

\section{Introduction}

Food security has always been a staple of discussion. Investigations have indicated that insects pose a great threat to global food security by damaging food crops and other food products derived from plants [1]. However, several pests show resistance, and the utilization of existing insecticides has more or less some side effects. For example, many of them can be lethal to nontarget organisms, and the residues of insecticides in crops also have negative impacts on human beings and the environment $[2,3]$. Tribolium castaneum is a species of beetle that is considered as a worldwide pest affecting mainly stored food products, such as grains, flour, and cereals, among others. These are dominant populations of insects found in stored traditional Chinese medicines [4]. T. castaneum can damage a great range of food and processed products, leading to agglomeration, discoloration, and spoilage, which result in serious economic losses [5]. The principal method to control these insects is the use of synthetic insecticides or fumigants. However, these methods may cause health hazards to warm-blooded animals, lead to environmental pollution, and potentially bring about insecticide-resistant insects, resulting in pest 
resurgence [6]. When dealing with food storage and preserving cultural relics and archives, it is essential to not only protect these materials from pests but to also reduce the extent of pesticide residues and avoid pollution. Therefore, an increasing number of researchers are searching and investigating different active natural products as botanical insecticides [7,8].

The essential oils extracted from various plants exhibit unique botanical and medicinal uses that, upon proper application, may not cause detrimental effects in humans and animal health as well as the environment. Essential oils are proven to have significant effects against a large number of stored grain insects, acting through ingestion [9] and contact toxicity [10,11]. The modes of action of plant essential oils on pests may include contact toxicity, fumigant, antifeedant, repellent, and growth-inhibiting activities [12,13]. Essential oils and their constituents from many plants have previously been confirmed to contain insecticidal or repellent activity, which inhibit the growth of insects that damage stored products [14-16]. Plant essential oils are often complex mixtures of terpenoids, and their bioactivity is likely to frequently be a result of synergy among constituents [17]. In addition, essential oils and their mono- and sesquiterpenoid constituents are fast-acting neurotoxins in insects, possibly interacting with multiple types of receptors [18]. Research has shown that, for rosemary (Rosemarinus officinalis) and lemongrass (Cymbopogon citratus) oils, synergy among major constituents results from increased penetration of toxicants through the insect's integument rather than through inhibition of detoxicative enzymes $[19,20]$. Moreover, these essential oils are volatile, and the products are also not risky for other organisms [21].

Elsholtzia ciliata (Thunb.) Hyland is a widely spread plant in China and is part of the herbal medicine collection with distinct special aroma [22-25]. The essential oils of Elsholtzia have certain poisonous activity on a variety of storage pests [26]. The E. ciliata essential oil was found to possess fumigant toxicity and contact toxicity against Liposcelis bostrychophila, with a lethal dose $50\left(\mathrm{LC}_{50}\right)$ value of $475.2 \mu \mathrm{g} / \mathrm{L}$ and $145.5 \mu \mathrm{g} / \mathrm{cm}^{2}$, respectively [27]. The ether extract of Elsholtzia stauntonii had a strong fumigation effect on adult Sitophilus zeamais and T. castaneum. After four days of treatment, the adult mortality of S. zeamais reached over $95 \%$, while it reached $100 \%$ for T. castaneum [28]. However, a literature survey showed no reports on insecticidal activity of the essential oil from the aerial parts of E. ciliata against $T$. castaneum. The present study was therefore undertaken to investigate the chemical components and insecticidal activities of the essential oil, including its active biochemical constituents against the food storage pest $T$. castaneum.

Carvone is a component of caraway (Carum carvi Linnaeus), dill (Anethum graveolens Linnaeus), and spearmint (Mentha spicata Linnaeus) seeds [29]. It is widely used in pesticides, food flavoring, feed flavoring, feed additive, personal care products, and veterinary medicine [30]. Limonene is listed in the Code of Federal Regulations as a generally recognized as safe (GRAS) substance for flavoring agents. It is commonly used in food items, such as fruit juices, soft drinks, baked goods, ice cream, and pudding [31], and it can be directly used in perfumes. It is also used in many flavor formulas with safety amount up to 30\%, and the International Fragrance Association (IFRA) has no restrictions on it [32], although the potential occurrence of skin irritation necessitates regulation of this chemical as an ingredient in cosmetics. In conclusion, the use of limonene in cosmetics is safe under the current regulatory guidelines for cosmetics [33,34].

A literature survey showed some reports on insecticidal activity of carvone and limonene against insects. For instance, Fang et al. [35] stated that carvone and limonene had contact toxicity against Sitophilus zeamais with $\mathrm{LD}_{50}$ values of $2.79 \mu \mathrm{g} /$ adult and $29.86 \mu \mathrm{g} /$ adult, respectively. Carvone and limonene also possessed strong fumigant toxicity against S. zeamais $\left(\mathrm{LC}_{50}=2.76\right.$ and $\left.48.18 \mathrm{mg} / \mathrm{L}\right)$. Yang [36] found that, after $24 \mathrm{~h}$ exposure time, the mortalities of insects in carvone with three fumigant concentrations reached $100 \%$. In addition, the limonene showed contact toxicity against $T$. castaneum adults with a $\mathrm{LD}_{50}$ value of $14.97 \mu \mathrm{g} /$ adult [37]. 


\section{Materials and Methods}

\subsection{Plant Materials and Extraction of Essential Oil}

E. ciliata was gathered in Longxi County $\left(35^{\circ} 1^{\prime} \mathrm{N}\right.$ latitude, $104^{\circ} 27^{\prime}$ E longitude, altitude $\left.1880 \mathrm{~m}\right)$ in the Gansu province of China. To obtain the crude essential oil, the minced sample was connected to the distillation unit and condenser and maintained for $6 \mathrm{~h}$. Anhydrous $\mathrm{Na}_{2} \mathrm{SO}_{4}$ was added to the crude essential oil to remove all water residue. The volume of the pure essential oil was recorded and the yield was calculated. The prepared essential oil was stored in the refrigerator at $4{ }^{\circ} \mathrm{C}$ until use.

\subsection{Test Insects}

T. castaneum adults were inoculated into a mixture of whole wheat flour and yeast flour at a mass ratio of 10:1 and cultured in a constant temperature incubator at $30 \pm 1{ }^{\circ} \mathrm{C}$ with $75 \% \pm 5 \%$ relative humidity for $24 \mathrm{~h}$ dark treatment. All adult beetles used in the experiment were considered as adult stage after an eclosion time of 1-2 weeks. On the other hand, the test larvae [38] were six instar larvae with an approximate length of 5-6 $\mathrm{mm}$.

\subsection{Gas Chromatography-Mass Spectrometry (GC-MS) Analysis}

The GC-MS analysis was run on an Agilent $6890 \mathrm{~N}$ gas chromatograph connected to an Agilent $5973 \mathrm{~N}$ mass selective detector. They were equipped with a gas chromatography-flame ionization detector (GC-FID) and a HP-5MS $(30 \mathrm{~cm} \times 0.25 \mathrm{~mm} \times 0.25 \mu \mathrm{m})$ capillary column. The essential oil sample was diluted in $n$-hexane to obtain a $1 \%$ solution. The injector temperature was maintained at $250{ }^{\circ} \mathrm{C}$ with the volume injected being $1 \mu \mathrm{L}$. The flow rate of carrier gas (helium) was $1.0 \mathrm{~mL} / \mathrm{min}, \mathrm{with}$ the mass spectra scanned from 50 to $550 \mathrm{~m} / \mathrm{z}$.

The retention indices (RI) were determined from gas chromatograms using a series of $n$-alkanes $\left(C_{5}-C_{36}\right)$ under the same operating conditions. Based on RI, the chemical constituents were identified by comparing them with $n$-alkanes as a reference. The components of the essential oil were identified by matching their mass spectra with various computer libraries (Wiley 275 libraries, NIST 05, and RI from other literature) [39].

\subsection{Contact Toxicity}

The contact toxicity activities of E. ciliata essential oil and its main components were determined by the dot contact method [40]. The essential oil was diluted to five different concentration gradients $(5 \%, 3.3 \%, 2.2 \%, 1.48 \%, 0.98 \%)$ with $n$-hexane. A $0.5 \mu \mathrm{L}$ diluted solution was dropped on the torso of $T$. castaneum after being palsied by the freezing method. Then, the test insects were transferred to a glass bottle with a volume of $25 \mathrm{~mL}$. $n$-Hexane and pyrethrin were used as negative and positive controls, respectively. Each concentration was repeated 5 times, and 10 test insects were used for each assay. After $24 \mathrm{~h}$, the number of dead insects was recorded, and the mortality and corrected mortality were calculated. Insects that did not respond to a brush were considered dead. A similar experimental method was undertaken in testing the larval stage.

\subsection{Fumigant Toxicity}

Fumigant activities of E. ciliata essential oil and its main components against adults and larvae of T. castaneum were evaluated based on the method described by Wu et al. [41]. The essential oil was diluted with $n$-hexane to obtain five concentration gradients $(10 \%, 6.6 \%, 4.4 \%, 2.9 \%, 1.77 \%)$. Diluted liquids of $10 \mu \mathrm{L}$ were injected on the filter paper $\left(2.0 \mathrm{~cm}^{2}\right)$ and placed on the inside of the bottle cap. The bottle cap was quickly screwed up and wrapped by the sealing film to form a closed space after 20 s. $n$-Hexane was used as a negative control, whereas methyl bromide and phoxim were used as positive controls for adults and larvae, respectively. Each concentration was repeated 5 times and tested in 10 test insects in each assay. After $24 \mathrm{~h}$, the death of the test insects was observed and recorded, 
and the mortality and corrected mortality were calculated. The same experimental method was used to test the larval stage.

\subsection{Two Main Components Compounding}

We used the ten-point theory [42] that assumes that the half-lethal concentrations of A and B are determined by the virulence of $a$ and $b$. Hence, the $A+B$ mixture was evaluated by the co-toxic factor method. A total of 7 ratios were selected according to the corresponding concentration gradient order of 1:7, 2:6, 3:5, 4 4, 5:3, 6:2, and 7:1. The contact toxicity and fumigant toxicity methods were performed as described previously (Materials and Methods Sections 2.4 and 2.5). Three repetitions were done for each treatment, and a blank control was set.

\subsection{Data Analysis}

The $\mathrm{LC}_{50}\left(\mathrm{mg} / \mathrm{L}\right.$ air) and the $\mathrm{LD}_{50}(\mu \mathrm{g} /$ adult or larva) of the lethal activity were analyzed and calculated using SPSS 22.0 statistical software, and the corrected mortality was calculated by Abbott's formula. The determination of the synergistic effect was performed with combined toxicity evaluation using Sun Yunpei's co-toxicity method CTC (Co-toxicity index) [43]. The criteria were as follows: $80 \leq \mathrm{CTC} \leq 120$ indicated an additive effect, CTC $>120$ indicated a synergistic effect, and CTC $<80$ indicated an antagonistic effect. The calculations were as follows:

(1) Co-toxicity index $(\mathrm{CTC})=\mathrm{ATI} / \mathrm{TTI} \times 100 \%$

(2) Mixed virulence index $(\mathrm{ATI})=$ standard drug $\mathrm{LD}_{50} /$ mixture $(\mathrm{A}+\mathrm{B}) \mathrm{LD}_{50} \times 100 \%$

(3) Theoretical virulence index of $(\mathrm{A}+\mathrm{B})(\mathrm{TTI})=\mathrm{Va} \times \mathrm{Ma}+\mathrm{Vb} \times \mathrm{Mb} \mathrm{V}_{\mathrm{a}}=$ Virulence index of agent $\mathrm{A}$, $M_{a}=$ the mass fraction of agent $A$ in the mixture $V_{b}=$ Virulence index of agent $B, M_{b}=$ the mass fraction of agent $B$ in the mixture

(4) Single dose virulence index $(\mathrm{TI})=$ standard drug $\mathrm{LD}_{50} / \mathrm{LD}_{50}$ for the test agent $\times 100 \%$

\subsection{Chemicals}

Pyrethrins were purchased from Dr. Ehrenstorfer $\mathrm{GmbH}$, Augsburg, Germany with a concentration of $27 \%$. Phoxim were purchased from Dr. Ehrenstorfer $\mathrm{GmbH}$, Augsburg, Germany with a purity of 98.0\%; Carvone was purchased from Tishila (Shanghai) Chemical Industry Development Co., Ltd., China, with a purity of 99.0\%. Limonene was purchased from Shanghai Aladdin Biochemical Technology Co., Ltd., China, with a purity of $95.0 \%$.

\section{Results}

\subsection{Chemical Compounds of E. ciliata Essential Oil}

The essential oil extracted from the leaves of E. ciliata had a yield of $0.36 \%(V / m)$. The chemical compounds and relative contents of E. ciliata essential oil are shown in Table 1. In this study, we identified 16 compounds in E. ciliata essential oil, the main compounds were monoterpenoids and sesquiterpenes, with monoterpenoids accounted for $76.97 \%$, sesquiterpenes accounted for $20.61 \%$, and carvone was the highest monoterpenoid among all, while $\alpha$-caryophyllene had the highest content of sesquiterpenes. What is more, we observed four major components of E. ciliata essential oil, namely, carvone (31.6\%), limonene (22.05\%), $\alpha$-caryophyllene $(15.47 \%)$, and dehydroelsholtzia ketone $(14.86 \%)$. These components are distinct from previous works. For example, E. ciliata essential oil derived from Mao'er Mountain of northeastern China mainly constituted dehydroelsholtzia ketone $(68.35 \%)$ and elsholtzia ketone (25.19\%) [44]. More than 30 components were separated from the essential oil of E. ciliata in Changbai Mountains in northeastern China, and the main components were $\beta$-dehydrogeranione (51.77\%) and elsholtzia ketone (33.33\%) [45]. In addition, the elsholtzia ketone concentration in the essential oil from both Changbai Mountains and Mao'er Mountain in the Liu's research was higher than that in this experiment. The dehydroelsholtzia ketone in the essential oil 
from Mao'er Mountain (68.35\%) in Liu's research was double that of this experiment. All the E. ciliata in the abovementioned works were gathered from Northeast China, while the E. ciliata studied in this paper was from Northwest China. The large climate difference between the two areas may be one of the reasons for the differences in essential oil composition. Moreover, the difference in harvesting time and growth years may also cause differences in essential oil components.

Table 1. Chemical composition of the essential oil from E. ciliata.

\begin{tabular}{|c|c|c|c|c|}
\hline Number & Constituent & $\begin{array}{c}\text { Retention } \\
\text { Time/Min (Rt) }\end{array}$ & $\mathbf{R i}$ * & $\begin{array}{l}\text { Relative Content } \\
(\%)\end{array}$ \\
\hline 1 & $\alpha$-Pinene & 3.394 & 932 & 0.55 \\
\hline 2 & $\beta$-Pinene & 3.812 & 977 & 0.74 \\
\hline 3 & Myrcene & 3.861 & 988 & 1.02 \\
\hline 4 & $\beta$-Phellandrene & 3.966 & 1019 & 0.19 \\
\hline 5 & Limonene & 4.464 & 1040 & 22.05 \\
\hline 6 & $\beta$-Ocimene & 4.654 & 1061 & 4.08 \\
\hline 7 & Linalool & 5.367 & 1090 & 0.83 \\
\hline 8 & Elsholtzia ketone & 6.726 & 1199 & 1.02 \\
\hline 9 & Carvone & 7.366 & 1216 & 31.63 \\
\hline 10 & $\begin{array}{l}\text { Dehydroelsholtzia } \\
\text { ketone }\end{array}$ & 8.104 & 1277 & 14.86 \\
\hline 11 & Cubebene & 9.180 & 1344 & 1.06 \\
\hline 12 & $\beta$-Bourbonene & 9.635 & 1379 & 0.44 \\
\hline 13 & $\beta$-Caryophyllen & 10.077 & 1414 & 2.92 \\
\hline 14 & $\alpha$-Caryophyllene & 10.397 & 1450 & 15.47 \\
\hline 15 & $\begin{array}{l}\text { (-)-Humulene } \\
\text { epoxide II }\end{array}$ & 10.643 & 1454 & 0.25 \\
\hline 16 & $\alpha$-Farnesene & 11.965 & 1489 & 0.47 \\
\hline- & $\begin{array}{c}\text { Total } \\
\text { Others }\end{array}$ & - & - & $\begin{array}{l}97.58 \\
2.42\end{array}$ \\
\hline
\end{tabular}

* RI (retention index) as determined on a HP-5MS column using the homologous series of $n$-hydrocarbons.

\subsection{Contact Activity}

Table 2 shows the results of contact activities of E. ciliata essential oil and the two main components (carvone and limonene) against T. castaneum adults and larvae. The essential oil of E. ciliata showed obvious contact toxicity against $T$. castaneum adult and larval stages with $\mathrm{LD}_{50}$ of $7.79 \mu \mathrm{g} / \mathrm{adult}$ and $24.87 \mu \mathrm{g} /$ larva, respectively. Among the two main components, carvone had stronger contact activity against adults $\left(\mathrm{LD}_{50}=5.08 \mu \mathrm{g} /\right.$ adult $)$, which was 7.59 -fold higher than the effect of limonene $\left(\mathrm{LD}_{50}=38.57 \mu \mathrm{g} / \mathrm{adult}\right)$. This result implies that carvone might have been a key component of E. ciliata essential oil involved in contact toxicity against T. castaneum. Although the contact activities of essential oil and carvone against $T$. castaneum adults was weaker than that of the positive control pyrethrin $\left(\mathrm{LD}_{50}=0.09 \mu \mathrm{g} / \mathrm{adult}\right)$, the E. ciliata essential oil showed stronger contact effect than previously reported plants. For example, Wu et al. [41] found that the $\mathrm{LD}_{50}$ of Platycladus orientalis essential oil against T. castaneum was $48.59 \mu \mathrm{g} /$ adult. The essential oils of Murraya exotica aerial parts showed contact toxicity against $T$. castaneum adults with $\mathrm{LD}_{50}$ values of $20.94 \mu \mathrm{g} /$ adult [46]. Therefore, E. ciliata essential oil and its two main components (carvone and limonene) have strong contact toxicity against $T$. castaneum. 
Table 2. Contact toxicity of E. ciliata essential oil and its main constituents against T. castaneum.

\begin{tabular}{ccccccc}
\hline $\begin{array}{c}\text { T. } \\
\text { castaneum }\end{array}$ & Treatment & $\begin{array}{c}\mathbf{L d}_{\mathbf{5 0}} \\
(\mathbf{m g} / \text { Adult) }\end{array}$ & $\begin{array}{c}\text { 95\% Fl } \\
(\mathbf{m g} / \text { Adult) }\end{array}$ & Slope \pm Se & $\boldsymbol{p}$-Value & $\begin{array}{c}\text { Chi Square } \\
\mathbf{X}^{\mathbf{2}}\end{array}$ \\
\hline \multirow{5}{*}{ Adult } & Essential oil & 7.79 & $6.96-8.65$ & $4.14 \pm 0.46$ & 0.85 & 16.17 \\
& Carvone & 5.08 & $4.19-6.20$ & $4.30 \pm 0.46$ & 0.01 & 44.15 \\
& Limonene & 38.57 & $34.48-43.09$ & $3.84 \pm 0.42$ & 0.55 & 21.54 \\
& Pyrethrin & 0.09 & $0.08-0.11$ & $2.48 \pm 0.31$ & 0.92 & 14.27 \\
\hline \multirow{5}{*}{ Larva } & Essential oil & 24.87 & $19.55-30.69$ & $1.69 \pm 0.22$ & 0.64 & 24.72 \\
& Carvone & 33.03 & $26.55-41.26$ & $1.86 \pm 0.23$ & 0.75 & 18.12 \\
& Limonene & 49.68 & $34.10-84.04$ & $0.95 \pm 0.15$ & 0.54 & 26.70 \\
& Pyrethrin & 1.31 & $0.75-2.17$ & $0.80 \pm 0.10$ & 0.82 & 16.72 \\
\hline
\end{tabular}

\subsection{Fumigation Activity}

Fumigation activity of E. ciliata essential oil and its two components are shown in Table 3. Both E. ciliata essential oil and the two major components had obvious fumigant toxicity against $T$. castaneum adults and larvae, although $E$. ciliata essential oil had a stronger fumigating effect on $T$. castaneum larvae $\left(\mathrm{LC}_{50}=8.73 \mathrm{mg} / \mathrm{L}\right.$ air $)$. The fumigant toxicity of carvone against adults $\left(\mathrm{LC}_{50}=4.34 \mathrm{mg} / \mathrm{L}\right.$ air) was significantly higher than that against larvae $\left(\mathrm{LC}_{50}=28.71 \mathrm{mg} / \mathrm{L}\right.$ air $)$. Limonene also had obvious fumigation activity against adults, with a $\mathrm{LC}_{50}$ of $5.52 \mathrm{mg} / \mathrm{L}$ air. The fumigation effect of carvone and limonene was 2.68 and 2.1 times greater, respectively, than the effect of the essential oil against adults. When the two components were applied together, the fumigation activity increased significantly. A previous study has also reported that carvone and limonene have strong fumigation activity against $T$. castaneum [36]. Therefore, it can be inferred that carvone and limonene are two of the active ingredients containing fumigant toxicity against $T$. castaneum.

For the fumigation effect against larvae, E. ciliata essential oil had the best fumigation activity, which was 3.29 times higher than the effect of carvone and 2.36 times higher than that of limonene. The fumigation activity of E. ciliata essential oil and the two components appeared weak. The fumigation activity of essential oil was 6-fold weaker than the positive control, and the fumigation activities of carvone and limonene against $T$. castaneum adults was weaker than methyl bromide. However, compared with the fumigation effect of other essential oils, E. ciliata essential oil and the two monomers had relatively stronger activity. For instance, Han et al. [47] reported eugenol had contact toxicity against $T$. castaneum larvae and adults with $\mathrm{LC}_{50}$ values of $219.00 \mu \mathrm{L} / \mathrm{mL}$ and $363.08 \mu \mathrm{L} / \mathrm{mL}$, respectively. In addition, Lv et al. [48] used Soxhlet extraction and ether as a solvent to extract essential oils from garlic, chili powder, citrus peel, and toon bark, which showed fumigation activity against $T$. castaneum larvae but not against adults. Given the characteristic of E. ciliata essential oil, it is most likely to develop a fumigant insecticide effect against the larvae of $T$. castaneum.

In summary, the contact toxicity of E. ciliata essential oil and its components against adult T. castaneum was significantly stronger than that against larvae. A pertinent point in this case is the completion of T. castaneum metamorphosis. The adults and larvae of T. castaneum are very different [49], especially in terms of self-protection mechanisms and body substances, such as the numerous enzymes that contribute to different degrees of tolerance to external stimuli. In addition, Liang et al. [50] also proved that these two forms differ greatly in their responses to various substances. As described in the literature, the main constituents of the defensive secretions of T. castaneum are methyl quinone, 1-pentadecene, 1,6-heptadecadiene, and paeonol. These compounds are repellent to adults whilst being attractive to larvae. Moreover, older adults are more sensitive to these compounds than young adults. Therefore, the whole process of metamorphosis diversifies the response to specific substances, which in turn leads to E. ciliata essential oil or its components having dramatically different contact activity against $T$. castaneum adults and larvae. In addition, according to the literature, monoterpenoids and sesquiterpenoid constituents are fast-acting neurotoxins in insects [18]. Both carvone and limonene are monoterpenoids, so it is speculated that carvone and limonene act as fast-acting neurotoxins on 
pests. In future research, the fumigating mechanism of carvone and limonene will be further explored. In addition, we shoule consider bioactive confrontation of high elsholtzia ketone or dehydroelsholtzia ketone Elsholtzia oils with those containing mostly carvone. We also need to consider chiral GC of oil and completion of R- and S-carvone together with R- and S-limonene to use in insect assays.

Table 3. Fumigant toxicity of E. ciliata essential oil and its main constituents against T. castaneum.

\begin{tabular}{|c|c|c|c|c|c|c|}
\hline $\begin{array}{c}T . \\
\text { castaneum }\end{array}$ & Treatment & $\begin{array}{c}\mathrm{LC}_{50}(\mathrm{mg} / \mathrm{L} \\
\text { Air })\end{array}$ & $\begin{array}{c}\text { 95\% FL } \\
\text { (mg/L Air) }\end{array}$ & Slope \pm SE & $p$-Value & $\begin{array}{c}\text { Chi Square } \\
X^{2}\end{array}$ \\
\hline \multirow{4}{*}{ Adult } & Essential oil & 11.61 & $9.21-14.01$ & $4.39 \pm 0.47$ & 0.00 & 87.62 \\
\hline & Carvone & 4.34 & $3.90-4.84$ & $6.27 \pm 0.83$ & 0.98 & 7.89 \\
\hline & Limonene & 5.52 & $2.75-9.22$ & $1.69 \pm 0.47$ & 0.83 & 5.85 \\
\hline & Methyl bromide ${ }^{a}$ & 1.83 & $1.43-2.23$ & $4.90 \pm 0.51$ & 0.89 & 8.67 \\
\hline \multirow{4}{*}{ Larva } & Essential oil & 8.73 & $6.62-11.25$ & $1.42 \pm 0.17$ & 0.99 & 11.19 \\
\hline & Carvone & 28.71 & $23.07-36.05$ & $1.63 \pm 0.15$ & 0.36 & 35.41 \\
\hline & Limonene & 20.64 & $16.96-25.56$ & $1.71 \pm 0.16$ & 0.86 & 24.46 \\
\hline & Phoxim & 1.05 & $1.23-2.08$ & $1.65 \pm 0.45$ & 0.89 & 3.25 \\
\hline
\end{tabular}

${ }^{a}$ The data for methyl bromide was derived from the literature with a consistent experimental method [51].

\subsection{Carvone Mixed with Limonene and Its Contact Toxicity against T. castaneum Adult}

After mixing carvone and limonene in seven different ratios, as shown in Table 4, we found that when the volume ratio of carvone to limonene was 2:6, the CTC value was 134.33, suggesting a synergistic effect $(\geq 120)$. On the other hand, when the volume ratio was $1: 7$, the CTC showed an additive effect (between 80 and 120). In other ratios, the respective CTCs were less than 80, suggesting an antagonistic effect. As shown in the results, the effect of the limonene mixture appeared unsatisfactory. One of the possible reasons may be that carvone and limonene work in a similar manner; as a result, the addition of limonene inhibits the contact toxicity effect of carvone. The proportion of carvone in E. ciliata essential oil was 1.67 times higher than that of limonene, which was equivalent to a compounding agent having a volume ratio of 5:3; the CTC was 67.43 (less than 80), indicating an antagonistic effect. This indicates that the contact toxicity of $E$. ciliata essential oil against $T$. castaneum adults may not be as strong as the contact activity of carvone.

Table 4. Contact toxicity and CTC () of carvone and limonene mixture against T. castaneum adults.

\begin{tabular}{ccccccc}
\hline $\begin{array}{c}\text { Volume } \\
\text { Ratio }\end{array}$ & $\begin{array}{c}\mathbf{L D}_{\mathbf{5 0}} \\
(\boldsymbol{\mu} \text { /Adult })\end{array}$ & Slope \pm SE & $\boldsymbol{p}$-Value & ATI & TTI & CTC \\
\hline $1: 7$ & 24.60 & $2.935 \pm 0.59$ & 0.64 & 20.65 & 24.02 & 85.97 \\
$2: 6$ & 10.84 & $2.972 \pm 0.51$ & 0.54 & 46.85 & 34.88 & 134.33 \\
$3: 5$ & 34.43 & $1.856 \pm 0.45$ & 0.99 & 14.75 & 45.73 & 32.26 \\
$4: 4$ & 39.60 & $1.970 \pm 0.47$ & 0.99 & 12.83 & 113.17 & 11.33 \\
$5: 3$ & 140.30 & $1.605 \pm 0.79$ & 0.60 & 3.62 & 67.43 & 5.37 \\
$6: 2$ & 79.34 & $1.666 \pm 0.95$ & 0.95 & 6.40 & 78.29 & 8.18 \\
$7: 1$ & 434.82 & $1.495 \pm 0.85$ & 0.80 & 1.17 & 115.93 & 1.01 \\
\hline
\end{tabular}

The contact toxicity of carvone against $T$. castaneum larvae displayed enhanced activity by combining in different ratios with limonene. As shown in Table 5, three of the seven ratios had CTC greater than 120 (synergism); these were 1:7, 2:6, and 7:1. In particular, carvone in a 1:7 ratio combination with limonene showed a significant increase in its activity over a single compound with a CTC value of 155 . This combination provided strong contact toxicity with the corresponding $\mathrm{LD}_{50}$ of $30.04 \mu \mathrm{g} /$ larva after $24 \mathrm{~h}$ of incubation. Besides, when carvone and limonene were mixed in volume ratios of 2:6 and 7:1, the CTC values were 144.08 and 130.19, respectively. The CTCs of these effective combinations were all more than 120 , suggesting a synergistic effect. However, when carvone and limonene were mixed in a ratio of 5:3, the CTCs were less than 80 , with an antagonistic effect. The 5:3 
ratio is similar to the carvone and limonene content ratio in essential oils. Essential oils have stronger contact toxicity against larvae than carvone and limonene, which appears to be a result of synergy among various constituents.

Table 5. Contact toxicity and CTC of carvone and limonene mixture against larvae of T. castaneum.

\begin{tabular}{ccccccc}
\hline $\begin{array}{c}\text { Volume } \\
\text { Ratio }\end{array}$ & $\begin{array}{c}\text { LD } \\
(\mu \mathrm{g} / \text { Larva) }\end{array}$ & Slope \pm SE & $\boldsymbol{p}$-Value & ATI & TTI & CTC \\
\hline $1: 7$ & 30.04 & $2.323 \pm 0.59$ & 0.34 & 109.94 & 70.68 & 155.55 \\
$2: 6$ & 30.62 & $3.829 \pm 0.73$ & 0.71 & 107.87 & 74.87 & 144.08 \\
$3: 5$ & 84.30 & $1.145 \pm 0.14$ & 0.88 & 39.18 & 79.06 & 49.56 \\
$4: 4$ & 405.96 & $1.390 \pm 0.12$ & 0.46 & 8.14 & 83.24 & 9.77 \\
$5: 3$ & 66.30 & $3.074 \pm 0.16$ & 0.95 & 49.82 & 87.43 & 56.98 \\
$6: 2$ & 112.98 & $2.175 \pm 0.94$ & 0.90 & 29.24 & 91.62 & 31.91 \\
$7: 1$ & 26.48 & $5.321 \pm 0.11$ & 0.96 & 124.74 & 95.81 & 130.19 \\
\hline
\end{tabular}

Table 6 shows the fumigation activity of carvone and limonene mixed in different ratios against the adult stage of T. castaneum. Out of these seven different ratios, the CTC of two particular ratios were greater than 120 (CTCs of 212.71 and 159.03), suggesting different degrees of synergism. Carvone + limonene at 1:7 ratio combination was found to be most effective in terms of fumigant toxicity against $T$. castaneum adults. This ratio provided strong fumigation activity with corresponding $\mathrm{LC}_{50}$ of $2.51 \mathrm{mg} / \mathrm{L}$ air after $24 \mathrm{~h}$ of incubation. The CTC values of the other ratios of carvone and limonene were less than 80 , showing an obvious antagonistic effect.

Table 6. Fumigant toxicity and CTC of carvone and limonene mixture against adult of T. castaneum.

\begin{tabular}{ccccccc}
\hline $\begin{array}{c}\text { Volume } \\
\text { Ratio }\end{array}$ & $\begin{array}{c}\text { LC }_{\mathbf{5 0}}(\mathbf{m g} / \mathrm{L} \\
\text { Air) }\end{array}$ & Slope \pm SE & $p$-Value & ATI & TTI & CTC \\
\hline $1: 7$ & 2.51 & $2.921 \pm 0.48$ & 0.00 & 172.91 & 81.29 & 212.71 \\
$2: 6$ & 3.25 & $4.793 \pm 0.63$ & 0.05 & 133.54 & 83.97 & 159.03 \\
$3: 5$ & 7.43 & $2.845 \pm 0.93$ & 0.80 & 58.41 & 86.64 & 67.42 \\
$4: 4$ & 6.55 & $2.656 \pm 0.82$ & 0.72 & 66.26 & 89.31 & 74.19 \\
$5: 3$ & 9.45 & $2.567 \pm 0.76$ & 0.88 & 45.93 & 91.98 & 49.93 \\
$6: 2$ & 11.39 & $2.814 \pm 0.44$ & 0.85 & 38.10 & 94.66 & 40.25 \\
$7: 1$ & 26.30 & $1.889 \pm 0.40$ & 0.72 & 16.50 & 97.33 & 16.95 \\
\hline
\end{tabular}

After the carvone and limonene were mixed in different ratios, the fumigation activity and CTC of the larvae of T. castaneum were determined (Table 7). The mixtures of carvone and limonene at 5:3 ratio showed fumigant activity against adult $T$. castuneum $\left(\mathrm{LC}_{50}=20.58 \mathrm{mg} / \mathrm{L}\right.$ air). Its CTC value was 89.65 , and it appeared to show an additive effect. The values of CTC under other ratios were all less than 80 and thus suggested an antagonistic effect.

Table 7. Fumigant toxicity and CTC of carvone and limonene mixture against larvae of T. castaneum.

\begin{tabular}{ccccccc}
\hline $\begin{array}{c}\text { Volume } \\
\text { Ratio }\end{array}$ & $\begin{array}{c}\text { LC }_{\mathbf{5 0}}(\mathbf{m g} / \mathbf{L} \\
\text { Air) }\end{array}$ & Slope \pm SE & $p$-Value & ATI & TTI & CTC \\
\hline $1: 7$ & 38.56 & $1.846 \pm 0.70$ & 0.87 & 74.46 & 134.21 & 55.48 \\
$2: 6$ & 34.64 & $2.314 \pm 0.77$ & 0.80 & 82.88 & 129.32 & 64.09 \\
$3: 5$ & 31.08 & $2.201 \pm 0.71$ & 0.88 & 92.37 & 124.44 & 74.23 \\
$4: 4$ & 32.99 & $2.286 \pm 0.72$ & 0.94 & 87.03 & 119.55 & 72.79 \\
$5: 3$ & 27.93 & $3.041 \pm 0.79$ & 0.54 & 102.79 & 114.66 & 89.65 \\
$6: 2$ & 221.59 & $1.215 \pm 0.85$ & 0.81 & 12.96 & 109.76 & 11.80 \\
$7: 1$ & 52.91 & $3.189 \pm 0.46$ & 0.88 & 54.26 & 104.89 & 51.73 \\
\hline
\end{tabular}


Figure 1 shows a general synergistic effect and antagonistic effect (to some degree) with different mixture ratios in terms of contact toxicity against the adult and larval stages of T. castaneum. The figure also indicates a deviation in the CTC value trends between adult and larval stages. We observed that when the mixture ratio was 2:6, the CTC values for both stages were greater than 120 , which suggested synergism, particularly in larvae. The CTC value reached the maximum when carvone and limonene were mixed at a ratio of 1:7. This result implies that synergy for larvae is the best at a 1:7 ratio. However, at this ratio, the CTC value of adults was 85.97 , indicating an additive effect. In addition, when the mixture ratios were 3:5 and 4:4, the CTC value of the contact killing effect in adult and larval stages decreased significantly. The CTC of larvae showed an upward trend after 4:4, reaching 130.19 at a ratio of $1: 7$, indicating a synergistic effect. On the contrary, the effect on adult $T$. castaneum declined after the mixture ratio of $4: 4$ and reached 1.01 at the ratio of 7:1, indicating a marked antagonistic effect. In conclusion, except at the ratio of 4:4, the CTC values of the $T$. castaneum larvae were slightly higher than those of adults in the same ratios. It can be deducted that the contact toxicity effect of carvone and limonene on the larvae of T. castaneum is generally better than that of adults at the same ratio.

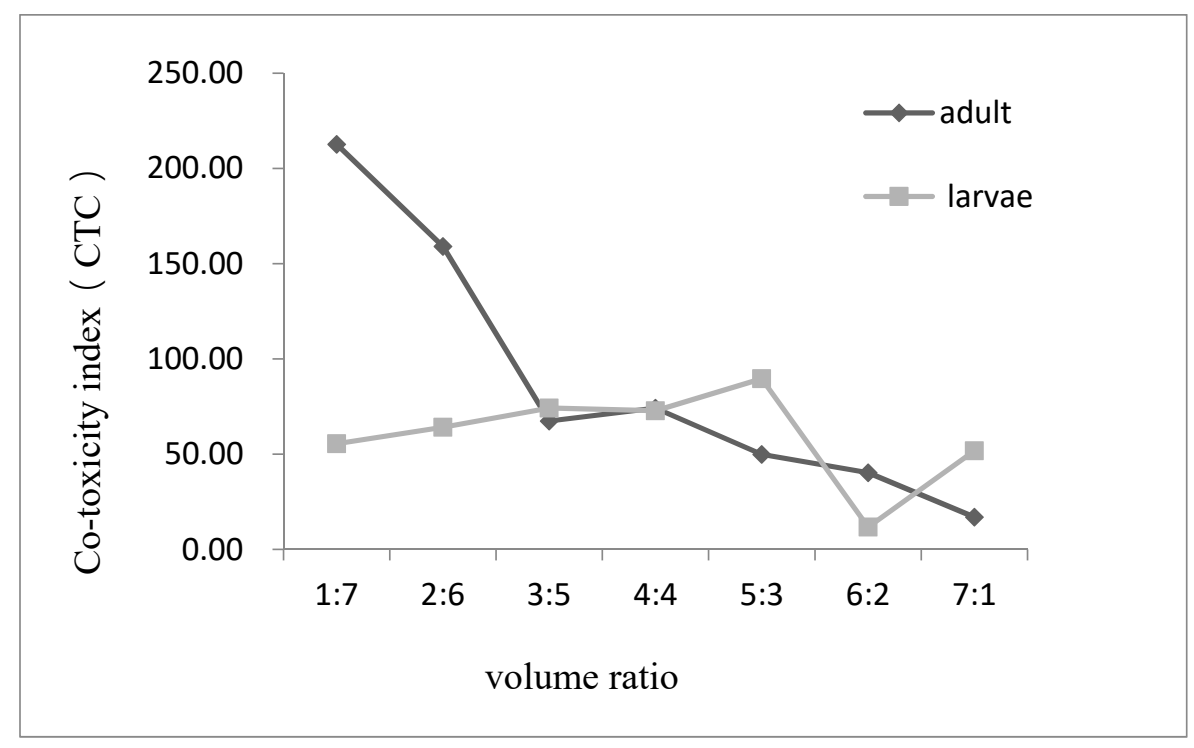

Figure 1. The CTC of contact activity of carvone and limonene at different ratios against adults and larvae of T. castaneum.

When carvone and limonene were mixed in different ratios, we observed obvious differences in fumigation activity against the adult and larval stages of T. castaneum (Figure 2). The CTC of adults reached the maximum value with the best synergistic effect at a ratio of 1:7. Moreover, the mixture showed a synergistic effect when the ratio was 2:6. After that, the value of CTC was less than 80, which indicated an antagonistic effect. However, the co-toxic effect against the larvae was generally weak or appeared antagonistic, except when the ratio was 5:3, which showed an additive effect. Generally, the CTC values of T. castaneum adults were slightly higher than the larvae using the same mixture ratio. Therefore, when carvone and limonene were mixed in the same ratio, its fumigation activity is better in adults than in larvae. 


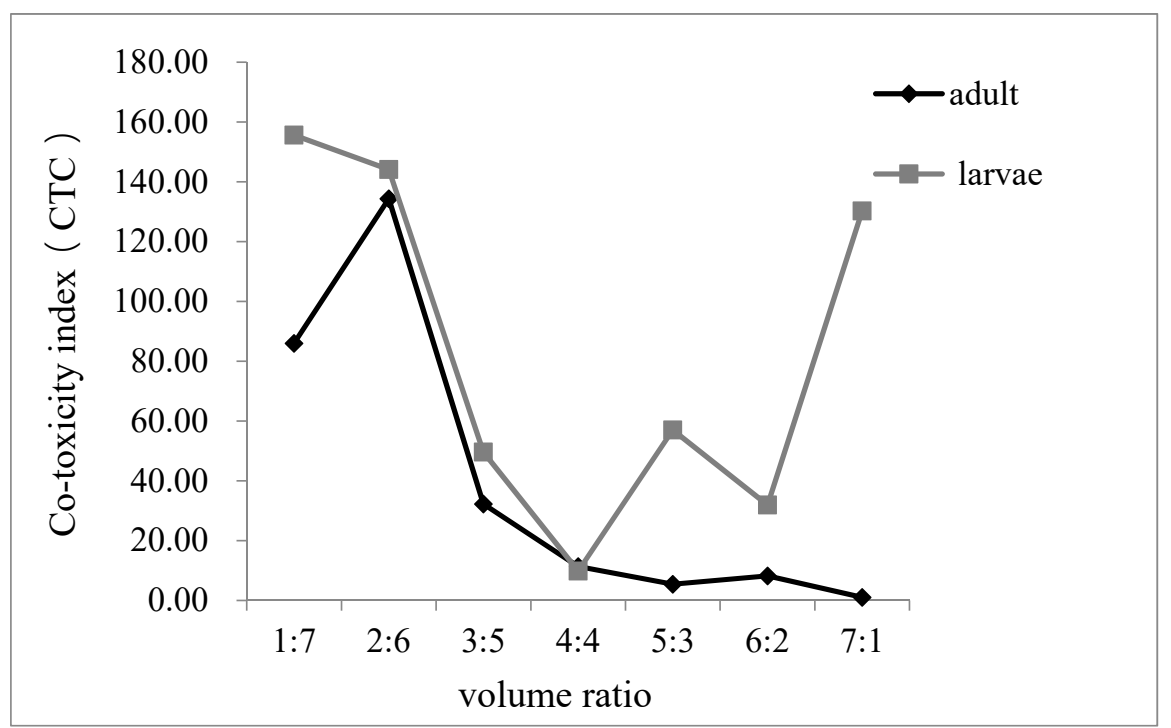

Figure 2. The CTC of fumigant activity of carvone and limonene at different ratios against adults and larvae of T. castaneum.

Through the mixture of the two major components, we identified the optimal mixing method that can effectively target $T$. castaneum. Changing the mixing ratio also changed the insecticide effects of the two compounds, but the effect of getting twice the result with half the effort was achieved for both plant essential oil mixed with compounds as well as essential oils mixed with essential oils. For example, the Commonwealth Scientific and Industrial Research Organisation (CSIRO) Institute of Entomology compared several natural plant extracts known to have insecticidal activity with ethyl formate and found that some plant products have a good synergistic effect [52]. The essential oils from plants have the advantages of having broad-spectrum insecticidal efficacy and being generally safe in humans, animals, and the environment. Carvone and limonene are derived from plant essential oil with the synergistic effect produced at a volume ratio of 2:6. The difference in the mode of action of the two substances against $T$. castaneum are important factors that influence its compounding effect. Exploring ways to make better use of mixed medicines will not only help overcome the high cost of plant essential oils but will also provide a theoretical basis for the practical application of the two medicines.

\section{Conclusions}

In this study, nine different components were identified from E. ciliata essential oil extract. The two main components, carvone and limonene, showed strong contact and fumigation activities against adults and larvae of T. castaneum. Meanwhile, E. ciliata essential oil also showed intense toxicity against the test insects. We also found that carvone might play a key role in the contact toxicity of E. ciliata essential oil against $T$. castaneum. Carvone and limonene exhibited synergistic effects at a volume ratio of 2:6. Altogether, our results suggest that $E$. ciliata essential oil extract and its two major components have a potential for downstream development as natural insecticides.

Author Contributions: Conceptualization, J.-Y.L., J.-L.W., and J.X.; Funding acquisition, J.-Y.L. and J.-L.W.; Investigation, J.-Y.L., J.X., Y.-Y.Y., Y.-Z.S. and F.Z.; Validation, J.-Y.L., Y.-Y.Y., Y.-Z.S., and F.Z.; Writing-original draft preparation, L.-J.Y. and J.X.; Writing-review \& editing, J.-Y.L., J.X., Y.-Y.Y., and Y.-Z.S.; Supervision, J.-L.W. and F.Z.; Project administration, J.-Y.L.; All authors have read and agreed to the published version of the manuscript.

Funding: This work was supported by the National Natural Science Foundation of China (NO. 81660632) and the Natural Science Foundation of Gansu Province, China (NO. 18JR3RA092).

Conflicts of Interest: The authors declare no conflict of interest. 


\section{References}

1. Athanassiou, C.G.; Arthur, F.H.; Throne, J.E. Efficacy of grain protectants against four psocid species on maize, rice and wheat. Pest Manag. 2009, 65, 1140-1146. [CrossRef] [PubMed]

2. Tapondjou, A.L.; Alder, C.; Bouda, H.; Fontem, D.A. Efficacy of powder and essential oil from Chenopodium ambrosioides leaves as post-harvest grain protectants against six-stored product beetles. J. Stored Prod. Res. 2002, 38, 395-402. [CrossRef]

3. Isman, M.B. Botanical insecticides, deterrents, and repellents in modern agriculture and an increasingly regulated world. Annu. Rev. Entomol. 2006, 51, 45-66. [CrossRef] [PubMed]

4. Wang, C.F.; Yang, K.; You, C.X.; Zhang, W.J.; Guo, S.S.; Geng, Z.F.; Du, S.S.; Wang, Y.Y. Chemical composition and insecticidal activity of essential oils from Zanthoxylum dissitum leaves and roots against three species of storage pests. Molecules 2015, 20, 7990-7999. [CrossRef] [PubMed]

5. Zhang, S.F.; Chen, H.J.; Xue, G.H. Atlas of Beetles Associated with Stored Products; China Agricultural Science and Technology Press: Beijing, China, 2008; p. 161. ISBN 978-78-0233-607-0.

6. Ebadollahi, A.; Safaralizadeh, M.H.; Pourmirza, A.A.; Gheibi, S.A. Toxicity of essential oil of Agastache foeniculum (Pursh) kuntze to Oryzaephilus surinamensis L. and Lasioderma serricorne F. Plant Prot. Res. 2010, 50, 215-219. [CrossRef]

7. Isman, M.B.; Singh, B.P. Botanical insecticides, deterrents, repellents and oils. Ind. Crops Uses 2010, 20, 433-445. [CrossRef]

8. Zettler, J.; Arthur, F.H. Chemical control of stored product insects with fumigants and residual treatments. Crops Prot. 2000, 19, 577-582. [CrossRef]

9. Fabres, A.; Janaina, C.M.D.S.; Fernandes, K.V.S.; Xavier-Filho, J.; Rezende, G.L.; Oliveira, A.E.A. Comparative performance of the red flour beetle Tribolium castaneum (Coleoptera: Tenebrionidae) on different plant diets. J. Pestic. Sci. 2014, 87, 495-506. [CrossRef]

10. Bossou, A.D.; Ahoussi, E.; Ruysbergh, E.; Adams, A.; Smagghe, G.D.; Kimpe, N.; Mangelinckx, S. Characterization of volatile compounds from three Cymbopogon species and Eucalyptus citriodora from benin and their insecticidal activities against Tribolium castaneum. Ind. Crops Prod. 2015, 76, 306-317. [CrossRef]

11. Lee, H.K.; Lee, H.S. Toxicities of active constituent isolated from Thymus vulgaris flowers and its structural derivatives against Tribolium castaneum (Herbst). Appl. Biol. Chem. 2016, 59, 821-826. [CrossRef]

12. Regnaltroger, C.; Vincent, C.; Arnason, J.T. Essential oils in insect control: Low-risk products in a High-Stakes World. Annu. Rev. Entomol. 2012, 57, 405-424. [CrossRef]

13. Chu, S.S.; Jiang, G.H.; Liu, W.L.; Liu, Z.L. Insecticidal activity of the root bark essential oil of Periploca sepium Bunge and its main component. Nat. Prod. Res. 2012, 26, 926-932. [CrossRef] [PubMed]

14. Omar, S.; Lalonde, M.; Marcotte, A. Insect growth-reducing and antifeedant activity in Eastern North America hardwood species and bioassay-guided isolation of active principles from Prunus serotina. Agric. For. Entomol. 2000, 2, 253-257. [CrossRef]

15. Ahmadi, M.; Abd-Alla, A.M.; Moharramipour, S. Combination of gamma radiation and essential oils from medicinal plants in managing Tribolium castaneum contamination of stored products. Appl. Radiat. Isot. 2013, 78, 16-20. [CrossRef] [PubMed]

16. Zhao, N.N.; Zhou, L.; Liu, Z.L.; Du, S.S.; Deng, Z.W. Evaluation of the toxicity of the essential oils of some common Chinese spices agaist Liposcelis bostrychophila. Food Control 2012, 26, 486-490. [CrossRef]

17. Tak,J.H.; Isman, M.B. Enhanced cuticular penetration as the mechanism for synergy of insecticidal constituents of rosemary essential oil in Trichoplusia ni. Sci. Rep. 2015, 5, 12690. [CrossRef]

18. Isman, M.B. Commercial development of plant essential oils and their constituents as active ingredients in bioinsecticides. Phytochem. Rev. 2019, 1-7. [CrossRef]

19. Tak, J.H.; Isman, M.B. Metabolism of citral, the major constituent of lemongrass oil, in the cabbage looper, Trichoplusia ni, and effects of enzyme inhibitors on toxicity and metabolism. Pestic. Biochem. Phys. 2016, 133, 20-25. [CrossRef]

20. Tak, J.H.; Jovel, E.; Isman, M.B. Effects of rosemary, thyme and lemongrass oils and their major constituents on detoxifying enzyme activity and insecticidal activity in Trichoplusia ni. Pestic. Biochem. Phys. 2017, 140, 9-16. [CrossRef] 
21. Aref, S.P.; Valizadegan, O.; Farashiani, M.E. The Insecticidal Effect of Essential Oil of Eucalyptus floribundi Against Two Major Stored Product Insect Pests; Rhyzopertha dominica (F.) and Oryzaephilus surinamensis (L.). J. Plant Prot. Res. 2015, 55, 35-41. [CrossRef]

22. Du, X.W.; Tan, J.C.; Cao, Y.F.; Zhang, X.H.; Chen, J.S. Research progress in plant essential oils. Hunan Agric. Sci. 2009, 8, 86-89. [CrossRef]

23. Neffati, A.; Bouhlel, I.; Sghaier, M.B.; Boubaker, J.; Limen, I.; Kilani, S.; Skandrani, I.; Bhouri, W.; Dauphin, J.L.; Barillier, D.; et al. Antigenotoxic and antioxidant activities of Pituranthos chloranthus essential oils. Environ. Toxicol. Pharmacl. 2009, 27, 187-194. [CrossRef] [PubMed]

24. Wu, K.G.; Luo, M.T.; Wei, H. Study on the antibacterial effect of 8 kinds of plant essential oils on common intestinal microorganisms in vitro. Mod. Food Sci. Technol. 2017, 6, 133-141.

25. Oke, F.; Aslim, B.; Ozturk, S.; Altundag, S. Essential oil composition, antimicrobial and antioxidant activities of Satureja cuneifolia Ten. Food Chem. 2009, 112, 874-879. [CrossRef]

26. Li, H.X.; Wei, M.S.; Yi, P.Y.; Ke, Z.G.; Man, Y.S. The control effect of 25 kinds of plant essential oils on the Callosobruchus maculatus. Grain Storage 2001, 30, 7-9.

27. Zhao, M.P.; Liu, X.C.; Lai, D.W.; Zhao, L.; Liu, Z.L. Analysis of the Essential Oil of Elsholtzia ciliata Aerial Parts and Its Insecticidal Activities against Liposcelis bostrychophila. Helv. Chim. Acta 2016, 99, 90-94. [CrossRef]

28. Lv, J.H.; Wu, S.H.; Yuan, L.Y.; Li, Y.F. Study on the effect of Elsholtzia stauntonii benth extract on the adults of Sitophilus zeamais and Tribolium rubra. J. Henan Univ. Technol. Nat. Sci. E 2008, 29, 31-34.

29. De Carvalho, C.C.; Da Fonseca, M.M.R. Carvone: Why and how should one bother to produce this terpene. Food Chem. 2006, 95, 413-422. [CrossRef]

30. Ma, C.; Liu, X.L.; Zhao, Z.G.; Zhang, L. Improvement on the synthesis of carvone perfume. J. Southwest Univ. Nat. Sci. Ed. 2003, 308-309, 340. [CrossRef]

31. Committee, E.S. Scientific Opinion on the safety assessment of carvone, considering all sources of exposure. EFSA J. 2014, 12, 1-74. [CrossRef]

32. Wang, W.J. Recent advances on limonene, a natural and active monoterpene. China Food Addit. 2005, 1, 33-37. [CrossRef]

33. Sun, J.D. D-limonene: Safety and clinical applications. Altern. Med. Rev. 2007, 12, 259-264. [CrossRef] [PubMed]

34. Kim, Y.W.; Kim, M.J.; Chung, B.Y. Safety Evaluation And Risk Assessment Of d-Limonene. J. Toxicol. Environ. Health 2013, 16, 17-38. [CrossRef] [PubMed]

35. Fang, R.; Jiang, C.H.; Wang, X.Y. Insecticidal Activity of Essential Oil of Carum Carvi Fruits from China and Its Main Components against Two Grain Storage Insects. Molecules 2010, 15, 9391-9402. [CrossRef]

36. Yang, B. Study on Fumigation Activity of Plant Essential Oil. D; Huazhong Agriculture University: Wuhan, China, 2008. [CrossRef]

37. Zhu, X.K.; Guo, S.S.; Zhang, Z. Insecticidal activities of the essential oil from Alpinia zerumbet leaves against Triboliun castaneum in storag. Plant Prot. 2017, 6, 151-155+162. [CrossRef]

38. Zhao, X.N.; Wang, J.Q. Study on the fumigant virulence of the oriental green pepper oil to the larvae of the Tribolium castaneum. Packag. Eng. 2012, 33, 9-13.

39. Adams, R.P. Identification of essential oil components by gas chromatography/mass spectrometry. J. Am. Soc. Mass Spectr. 2005, 16, 1902-1903. [CrossRef]

40. Yang, K.; Wang, C.F.; You, C.X. Bioactivity of essential oil of Litsea cubeba from China and its main compounds against two stored product insects. J. Asia Pac. Entomol. 2014, 17, 459-466. [CrossRef]

41. Wu, Y.; You, C.X.; Tian, Z.F. Insecticidal Activity of essential Oil from Vitex negundo L. var. cannabifolia Leaves on Lasioderma serricorne. Plant Prot. 2016, 42, 97-102. [CrossRef]

42. Chen, I.; Xu, H.H.; Li, Y.Y.; He, L.F.; Zhao, S.H. Discussion on the method of screening the best effective formula of pesticide compound. Acta Phytophys. Sin. 2000, 27, 349-354. [CrossRef]

43. Wang, S.X.; Yuan, H.B.; Ma, L.B.; Yang, C.H.; Reng, B.Z. Fumigation effect of plant essential oil mixed with ethyl formate on adults of Sitophilus zeamais. J. Northeast Norm. Univ. Nat. Sci. 2012, 44, 107-111.

44. Liu, X.P.; Jing, X.M. Study on chemical constituents and biological activities of E.ciliata essential oil. J. Heilongjiang Bayi Agric. Univ. 2018, 30, 1002-2090.

45. Jin, X.L.; Li, D.H. Component analysis of essential oil from wild E. ciliata fragrans in Changbai Mountain. J. Yanbian Univ. Nat. Sci. Ed. 1996, 1, 32-34. 
46. Li, W.Q.; Jiang, C.H.; Chu, S.S.; Zuo, M.X.; Liu, Z.L. Chemical Composition and Toxicity against Sitophilus zeamais and Tribolium castaneum of the Essential Oil of Murraya exotica Aerial Parts. Molecules 2010, 15, 5831-5839. [CrossRef] [PubMed]

47. Han, Q.X.; Huang, S.S. The biological activity of eugenol on the Tribolium castaneum. J. Chongqing Norm. Univ. Nat. Sci. Ed. 2009, 26, 16-19. [CrossRef]

48. Lv, J.H.; Wang, X.M.; Bai, X.G.; Lu, Y.J. Control of four plants essential oils against the Tribolium castaneum research. Henan Agric. Sci. 2006, 9, 68-71. [CrossRef]

49. Huang, Y.P.; Chen, Q.; Chen, M.D. Exploration Experiments on the Effects of Feeding Conditions on the Development and Reproductive Capacity of Tribolium castaneum. Biol. Teach. 2012, 37, 58-59. [CrossRef]

50. Liang, Y.S. Behavioral responses of the main components of defensive secretions of adult and larvae of the genus Tribolium castaneum. J. Chin. Cereals Oils Assoc. 1995, 4, 18-22.

51. Chen, H.P.; Yang, K.; You, C.X.; Du, S.S.; Cai, Q.; He, Q.; Geng, Z.F.; Deng, Z.W. Chemical constituents and biological activities against Tribolium castaneum (Herbst) of the essential oil from Citrus wilsonii leaves. J. Serbian Chem. Soc. 2014, 79, 1213-1222. [CrossRef]

52. Guo, D.L.; Pu, W.; Yan, X.P.; Tao, C. Research progress of modified atmosphere and fumigation of foreign countries-A review of the 8th Int'l Conference on Controlled Atmosphere and Fumigation Conference (CAF 2004). Grain Storage 2004, 32, 44-48. [CrossRef]

(C) 2020 by the authors. Licensee MDPI, Basel, Switzerland. This article is an open access article distributed under the terms and conditions of the Creative Commons Attribution (CC BY) license (http://creativecommons.org/licenses/by/4.0/). 